Japanese Journal of Physiology, 29, 459-470, 1979

\title{
Physicochemical Study of Receptive Mechanism of Laryngeal Water Fibers in the Rabbit
}

\author{
Tomio SHINGAI* \\ Department of Physiology, Akita University \\ School of Medicine, Akita, 010 Japan
}

\begin{abstract}
The effects of various cations on the water unit activity were studied by recording unitary discharges in the superior laryngeal nerve fibers of the rabbit. Chloride salts of $\mathrm{Li}^{+}, \mathrm{Na}^{+}, \mathrm{K}^{+}, \mathrm{Cs}^{+}$depressed the water response, while sulfate salts of $\mathrm{Li}^{+}, \mathrm{Na}^{+}, \mathrm{NH}_{4}{ }^{+}, \mathrm{K}^{+}$facilitated it. Cations were less effective in stimulating action than anions. The depression of the water response in the laryngeal nerve has been thought to be caused by permeation of the stimulating anions through the receptor membrane and/or by destruction of the water structure on the membrane surface induced by adsorbed anions (SHINGAI, $1977 \mathrm{a}$ ). In order to differentiate these two possible actions of anions, the effects of benzenesulfonate and trichloroacetate were examined, because these anions were expected to be impermeant through the receptor membrane and to have a water structure-breaking effect. These anions showed no effect on the water response in concentrations below $320 \mathrm{~mm}$. Measurements of the viscosity and the density of the electrolyte solutions showed that benzenesulfonate had a strong water structure-breaking effect. These results suggested that impermeant anions having water structure-breaking actions do not influence the excitability of the water receptor and that the depression of the water response by anions in the stimulating solution is caused by a hyperpolarization generated by permeation of the anions through the receptor membrane.
\end{abstract}

Laryngeal receptors responding to water have been found in the cat (STOREY, 1968; Boushey et al., 1974), lamb (STOREY and JoHnson, 1975), rabbit (SHINGAI, 1977 a), rat (ShINGAI, 1977 b) and monkey (HARDING et al., 1978). A study using water units in the superior laryngeal nerves by SHINGAI (1977 a) revealed that responses of the units to water were depressed by $\mathrm{SCN}^{-}, \mathrm{Br}^{-}, \mathrm{Cl}^{-}, \mathrm{I}^{-}, \mathrm{NO}_{3}{ }^{-}$in an aqueous solution and facilitated by $\mathrm{SO}_{4}^{2-}, \mathrm{IO}_{3}^{-}, \mathrm{F}^{-}, \mathrm{BrO}_{3}^{-}$. Physicochemically, anions are divided into two categories, water structure-breaking ions and water

Received for publication February 16, 1979

* Present address: Department of Physiology, Niigata University School of Dentistry, Niigata, 951 Japan

真貝富夫 
structure-making ions, according to their effects in changing the water structure surrounding the ions (FRANK and WEN, 1957). The depressing anions of the water response belong to the water structure-breaking ion group, while the facilitating anions belong to the water structure-making ion group. On the basis of this correspondence, SHINGAI (1977 a) proposed that the facilitation of the water response is caused by the water structure-making actions of anions by enhancing the organization of water structure on the receptor membrane surface and that the depression of the response is induced by water structure-breaking anions. However, the mechanism of the depression is not clear, because two different mechanisms of depression by depressing anions may be considered. One is a depression due to the water structure-breaking action of an anion adsorbed on the receptor membrane and the other is a depression caused by the hyperpolarization of the membrane arising from penetration of an anion through the membrane. The latter is because the ion sizes of depressing anions are relatively small, and because the finding that all depressing anions penetrate various cell membranes, e.g., post-synaptic membranes (e.g., ARAKI et al., 1961) and muscle fiber membranes (e.g., HAGIWARA and TAKAHASHI, 1974), implies the possibility of anion penetration through other cell membranes including the water receptor membrane of the rabbit.

The present study was carried out to extend the work of a previous paper (SHINGAI, 1977 a). First, the effects of cations on water unit activity were studied to learn the ion selectivity of the receptor membrane. Secondly, in order to examine the effect of destruction of the water structure on the receptor membrane surface caused by structure-breaking anions without the depressing effect due to the hyperpolarization of the membrane generated by permeation of the anions, sodium salts of benzenesulfonate and trichloroacetate were used because these anions have the following properties. They have large ion sizes, $5.0 \times 6.5 \AA$ for benzenesulfonate and $5.5 \times 6.0 \AA$ for trichloroacetate (WoOdBuRY and MiLES, 1973). Hence they, perhaps, do not penetrate the receptor membrane. In addition, these anions can be expected to have the water structure-breaking effect, because benzenesulfonate has a powerful salting-in effect (VOET, 1937) and trichloroacetate has a potent denaturing action (HAMAGUCHI and GEIDUSCHEK, 1962) (see DISCUSSION).

The viscosity and the density of the electrolyte solutions were measured to make sure whether benzenesulfonate and trichloroacetate are water structurebreaking anions or not.

The results will show that a destruction of the water structure on the receptor membrane surface which is produced by water structure-breaking anions does not affect the receptor membrane excitability and that the depression of the water response may be caused by hyperpolarization of the receptor membrane arising from permeation of the anions in the stimulating solution. 


\section{METHODS}

The experiments were performed on twenty rabbits $(1.7-4.0 \mathrm{~kg})$. The animals were anesthetized with urethane $(0.5-1.0 \mathrm{~g} / \mathrm{kg}$ i.v.) and placed in a supine position. They were immobilized with gallamine triethiodide (Teikoku Kagaku Indust. Co.) and artificially ventilated via tracheal canulae. The laryngeal mucosa was exposed by a midline incision in the thyroid cartilage and the edges of the incision were held apart by threads to expose the laryngeal surface of the epiglottis.

The superior laryngeal nerve was cut near its junction with the vagus nerve. Neural activity of the superior laryngeal nerve was recorded from fine strands containing one active unit using a bipolar silver electrode in a paraffin pool. The nerve impulses were displayed on an oscilloscope (Nihon Kohden Co. Type VC-7) and recorded on a magnetic tape.

Test solutions were applied to the laryngeal surface of the epiglottis using a syringe fitted with a fine needle. Stimulation was applied at intervals of 4-5 min to avoid being influenced by the preceding stimulation. Between periods of stimulation the receptive field was rinsed with $160 \mathrm{~mm} \mathrm{NaCl}$ solution. One droplet of distilled water $(6-8 \mu \mathrm{l})$ was sufficient to excite the water unit. Distilled water was made with an apparatus (Toyo Kagaku Indust. Co. Type GS-20N) and it had a specific conductance of less than $10^{-7} \Omega^{-1} \mathrm{~cm}^{-1}$. Distilled water was used as a standard solution and the responses to other solutions were compared with the water response. The magnitude of the response was measured as the number of impulses during the $5 \mathrm{sec}$ after stimulation. The temperature of the droplets of the solutions was maintained at $20-25^{\circ} \mathrm{C}$.

Density and viscosity measurements. For viscosity measurements, a CannonFenske-type viscosimeter (Sibata Chemical Apparatus Mfg. Co.) with a flow time for water at $35.00^{\circ} \mathrm{C}$ of 169.5 or $612.5 \mathrm{sec}$ was used. Flow times for water $\left(t_{0}\right)$ determined before and after a series of measurements often differed by $0.5 \mathrm{sec}$ and the mean was used in calculations. Densities were measured with a $47 \mathrm{~cm}^{3}$ pyknometer (Sibata Chemical Apparatus Co.). It was weighed using a chemical balance (Sartorius Type 2414). For both the density and the viscosity measurements, the temperature in the water bath was measured by a standard thermometer and kept at $35.00 \pm 0.02^{\circ} \mathrm{C}$ using a thermostat.

The individual readings for five viscosity measurements agreed with each other to within $0.2 \mathrm{sec}$ for a $170 \mathrm{sec}$ effusion time $(0.12 \%)$ and $0.4 \mathrm{sec}$ for a $600 \mathrm{sec}$ effusion time $(0.07 \%)$. Three measurements of density were made. The overall accuracy of the density measurements was estimated to be $\pm 0.002 \%$. Relative viscosity was calculated from the equation

$$
\eta_{\mathrm{r}}=\frac{d \cdot t}{d_{0} \cdot t_{0}}
$$

where $d$ indicates the density of the solution and $d_{0}$ is the density of water at $35.00^{\circ} \mathrm{C}(0.99403)$. 
RESULTS

\section{Effects of various cations}

The effects of monovalent cations on the activity of a water unit were examined at a concentration of $50 \mathrm{~mm}$ (Fig. 1). The responses of the water unit to chloride salts of $\mathrm{Li}^{+}, \mathrm{Na}^{+}, \mathrm{K}^{+}, \mathrm{Cs}^{+}$were less than the response produced by distilled water, the magnitude being about $50 \%$ of the water response. Differences in the magnitude of the response were small among cations. Sulfate salts of $\mathrm{Li}^{+}, \mathrm{Na}^{+}, \mathrm{NH}_{4}^{+}$ and $\mathrm{K}^{+}$elicited more vigorous responses than did water. Somewhat larger differences were observed among cations in the response produced by stimulation using sulfate salt solutions. The effect of $\mathrm{Li}^{+}$was similar to that of $\mathrm{Na}^{+}$in both cases. $\mathrm{Cs}^{+}, \mathrm{K}^{+}$and $\mathrm{NH}_{4}{ }^{+}$elicited larger responses than $\mathrm{Na}^{+}$and $\mathrm{Li}^{+}$, but the differences among cations were small compared with that between $\mathrm{Cl}^{-}$and $\mathrm{SO}_{4}^{2-}$. Differences in the response to various ions were similarly observed in other water units. Dominant factors in the depression and facilitation of the water response by chloride salts and sulfate salts may be due to $\mathrm{Cl}^{-}$and $\mathrm{SO}_{4}^{2-}$, respectively.

\section{Effects of benzenesulfonate and trichloroacetate}

In order to determine whether the depression of the water response is caused by the hyperpolarization of the receptor membrane generated by permeation of the anions in the stimulating solutions or by the water structure-breaking effects

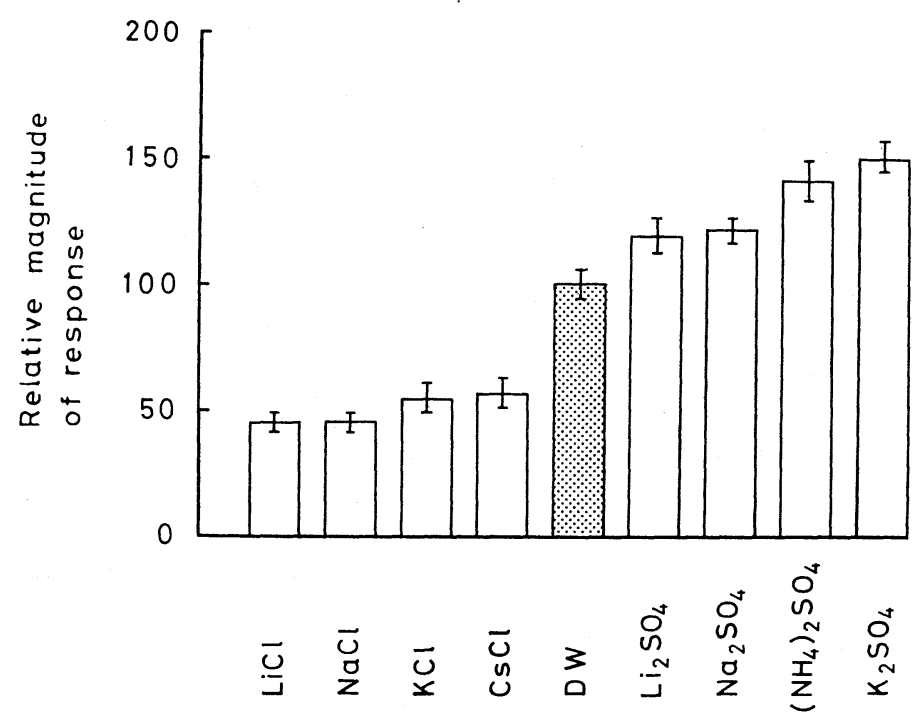

Fig. 1. Effects of various cations $(50 \mathrm{~mm})$ on the water response. The ordinate indicates the relative magnitude of responses produced by test solutions recorded from a water unit. The response induced by distilled water was represented as 100 . Each value represents mean \pm S.D. $(n=3-4)$. 


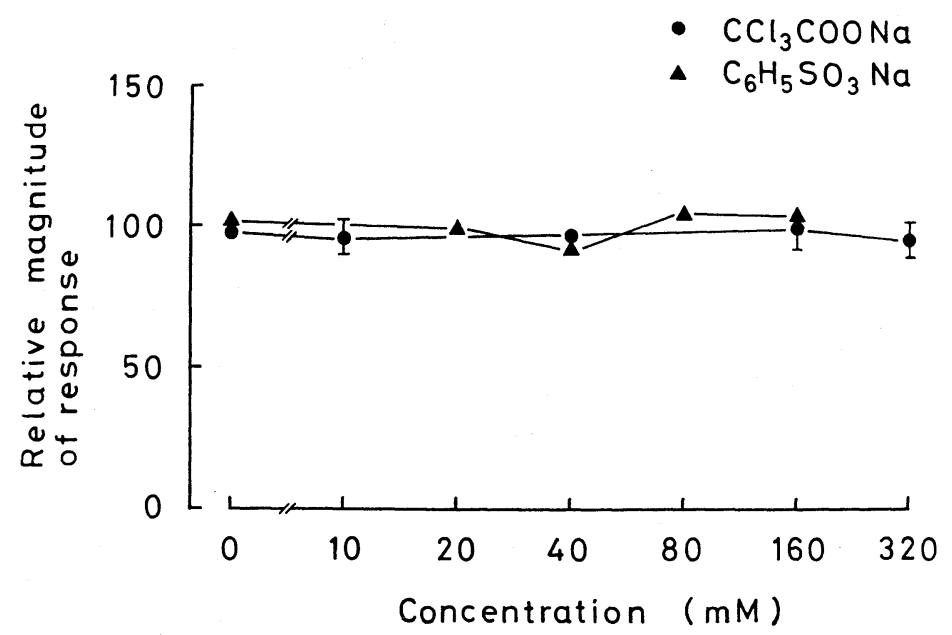

Fig. 2. Relations between the relative magnitude of responses and concentrations of sodium salts of benzenesulfonate and trichloroacetate. The ordinate indicates the relative magnitude of responses produced by test solutions recorded from a water unit. The response induced by distilled water was represented as 100 . Each point represents the mean of 2-3 measurements and vertical bars indicate S.D.

of adsorbed anions on the membrane surface, the effects of sodium salts of benzenesulfonate and trichloroacetate were examined.

The results are shown in Fig. 2. The responses induced by the solutions of these electrolytes were almost the same as that produced by distilled water in concentrations ranging from 10 to $320 \mathrm{~mm}$. The ineffectiveness of these electrolytes on water unit activity was also observed in other water units tested. The results suggest that $\mathrm{Na}^{+}$, benzenesulfonate and trichloroacetate have individually no appreciable effect on the activity of the water receptor.

Measurements of $B$-value and $\bar{V}^{\circ}$

In order to determine whether or not benzenesulfonate and trichloroacetate

Table 1. $B$-value, $\bar{V}^{\circ}$ and $B-0.0025 \bar{V}^{\circ}$ of ions.

\begin{tabular}{lccc}
\hline \multicolumn{1}{c}{ Ion } & $\begin{array}{c}B \text {-value } \\
\text { (liter/mol) }\end{array}$ & $\begin{array}{c}\nabla^{\circ} \\
\left(\mathrm{cm}^{3} / \mathrm{mol}\right)\end{array}$ & $\begin{array}{c}B-0.0025 \nabla^{\circ} \\
(\text { liter } / \mathrm{mol})\end{array}$ \\
\hline $\mathrm{SCN}^{-}$ & -0.048 & 46.1 & -0.163 \\
$\mathrm{Cl}^{-}$ & 0.006 & 23.6 & -0.053 \\
$\mathrm{C}_{6} \mathrm{H}_{5} \mathrm{SO}_{3}^{-}$ & 0.268 & 114.5 & -0.018 \\
$\mathrm{HCOO}^{-}$ & 0.123 & 28.7 & 0.051 \\
$\mathrm{CCl}_{3} \mathrm{COO}^{-}$ & 0.287 & 86.6 & 0.071 \\
$\mathrm{C}_{6} \mathrm{H}_{5} \mathrm{COO}^{-}$ & 0.356 & 96.6 & 0.115 \\
$\mathrm{CH}_{3} \mathrm{COO}^{-}$ & 0.239 & 45.1 & 0.126 \\
\hline
\end{tabular}

Temperature: $35.00 \pm 0.02^{\circ} \mathrm{C}$. 
are water structure-breaking ions, the $B$-value (coefficient of viscosity) and $\bar{V}^{\circ}$ (partial molal volume) for them and other several anions were calculated from the measurements of viscosity and density as described in APPENDIX, and are summarized in Table 1. The difference $B-0.0025 \bar{V}^{\circ}$ was used as a criterion for determining the net water structure effect of a solute. A positive value for $B-$ $0.0025 \bar{V}^{\circ}$ corresponds to a structure-making ion, while a negative value indicates a structure-breaking ion. The values for benzenesulfonate and trichloroacetate are -0.018 and +0.071 , respectively. To confirm the accuracy of the values, $B-0.0025 \bar{V}^{\circ}$ was plotted against the lyotropic number (VOET, 1937) in Fig. 3. The value for trichloroacetate is not shown in Fig. 3 because the position for the anion in the lyotropic series is not known. There is a good linear relationship between $B-0.0025 \bar{V}^{\circ}$ and the lyotropic numbers for inorganic anions, including $\mathrm{Cl}^{-}$and $\mathrm{SCN}^{-}$, whose values were obtained in the present study. However, there are large deviations from the linear relationship for the organic anions.

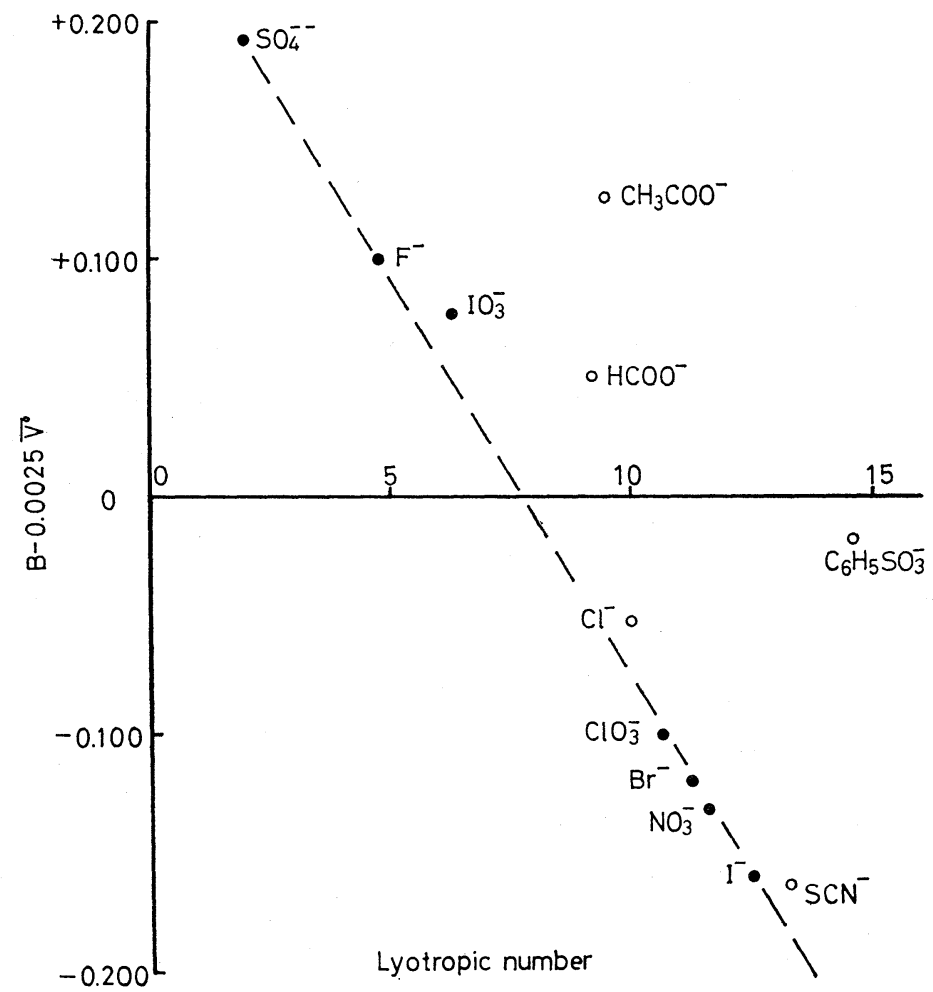

Fig. 3. Relations between $B-0.0025 \bar{V}^{\circ}$ and lyotropic numbers. Lyotropic numbers were quoted from the data of VOET (1937). $B-0.0025 \bar{V}^{\circ}$ for anions represented by open circles are taken from Table 1 and the values for anions shown by filled circles were calculated from the data of KAMINSKY (1957) and LALIBERTÉ and CONWAY (1970) and Millero (1971). 
The reasons for the deviations will be discussed later.

\section{DISCUSSION}

Since the activity of the water units used in the present study is dominantly influenced by anions, negatively-charged functional groups of ions may play an important role in the interaction between large organic ions and the receptor membrane. Therefore, in the case of benzenesulfonate, which consists of a benzene loop and a sulfonic group, the sulfonic group which is negatively charged may play an important role.

The value $B-0.0025 \bar{V}^{\circ}$ for benzenesulfonate obtained in the present paper is a negative value $(-0.018)$. Thus, benzenesulfonate belongs to a water structure-breaking ion. In the case of benzenesulfonate, however, there is a large deviation from the linear relationship between $B-0.0025 \bar{V}^{\circ}$ and the lyotropic numbers (Fig. 3). The deviation may be caused by the following factors. First, the shape of benzenesulfonate deviates from a sphere which was adopted in the Einstein equation as the ideal shape for colloidal suspensions (see APPENDIX). Secondly, the anion has a nonpolar group as well as a polar group. Since a benzene loop is hydrophobic, the loop has a water structure-making effect (hydrophobic hydration). This effect hinders the movement of ions and consequently increases the $B$-value. Thus, it is inferred that the sulfonic functional group itself should have a larger negative value of $B-0.0025 \bar{V}^{\circ}$ than the calculated value $(-0.018)$.

If the value of $B-0.0025 \bar{V}^{\circ}$ has an additive property, $B-0.0025 \bar{V}^{\circ}$ for the sulfonic group can be calculated using the values for formate and benzoate in Table 1 and the value for $\mathrm{H}^{+}(+0.084$, estimated from KAMINSKY's data (1957) and LALIBERTÉ and CONWAY (1970)). The estimated value was -0.166 , this being nearly equal to that for $\mathrm{SCN}^{-}(-0.163)$. The finding that benzenesulfonate has a powerful salting-in action to the same degree as does $\mathrm{SCN}^{-}$(VOET, 1937) supports this estimation.

$B-0.0025 \bar{V}^{\circ}$ for trichloroacetate obtained in this paper is +0.071 . Considering the deviation from the ideal suspension, this is a comparatively small positive value. This implies that the functional group of the ion (the carboxyl group) has a strong water structure-breaking effect. This inference is supported by the finding that trichloroacetate is a more potent denaturing agent of DNA than $\mathrm{SCN}^{-}$(HAMAgUCHI and GeIDUSCHEK, 1962). Since the denaturing action closely parallels the salting-in effect (HAMAGUCHI and GEIDUSCHEK, 1962), trichloroacetate is expected to have a strong salting-in effect comparable to that of $\mathrm{SCN}^{-}$. Therefore, the effective part of trichloroacetate (the carboxyl group) can be considered to have a large negative value of $B-0.0025 \bar{V}^{\circ}$ similar to that for $\mathrm{SCN}^{-}$. It is consequently inferred that a carboxyl group of trichloroacetate has a value of $B-0.0025 \bar{V}^{\circ}$, close to that for a sulfonic group of benzenesulfonate. The fact 
that benzenesulfonic acid and trichloroacetic acid have the same large dissociation constant $\left(2 \times 10^{-1} \mathrm{M}, \mathrm{p} K_{\mathrm{a}}=0.7\right)$ also supports the similarity of the properties of these two ions. The deviation of the obtained value $(+0.071)$ from the expected negative value may be caused by the same reasons considered in the case of benzenesulfonate.

Figure 4 illustrates the relationship between $B-0.0025 \bar{V}^{\circ}$ and relative magnitude of the response of water units to various anions including benzenesulfonate. The position for trichloroacetate is not shown in Fig. 4 , because $B-0.0025 \bar{V}^{\circ}$ for this ion was not calculated due to an absence of physical data. It is noteworthy that benzenesulfonate does not belong to the depressing ion group in spite of the large negative value of $B-0.0025 \bar{V}^{\circ}$ for its sulfonic group. This finding indicates that benzenesulfonate and trichloroacetate are impermeant anions through the receptor membrane, because if the membrane is permeable to these ions, the membrane potential is changed, and the response is affected by increased extracellular concentrations of these ions. This inference is acceptable because the sizes of these ions are large compared with the sizes of anion channels generally accepted.

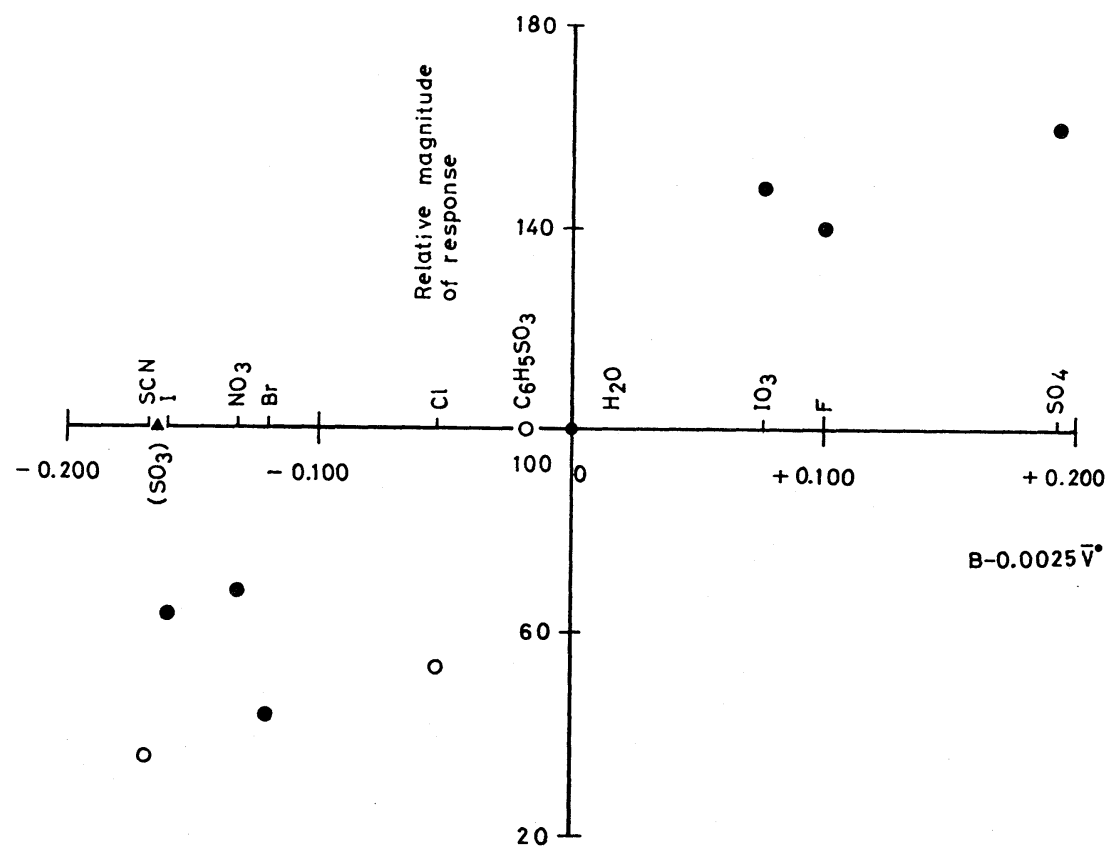

Fig. 4. Relations between the relative magnitude of responses and $B-0.0025 \bar{V}^{\circ}$. The data on neural responses were quoted from a previous paper (SHINGAI, 1977 a) except for benzenesulfonate. A filled triangle indicates the expected position for sulfonic group of benzenesulfonate and other notations are the same as those in Fig. 3. 
The ineffectiveness of benzenesulfonate and trichloroacetate on the water response also indicates that an impermeant anion having a negative value of $B-0.0025 \bar{V}^{\circ}$ does not influence membrane excitability. In other words, the water structure-breaking action of adsorbed anions on the receptor membrane surface does not influence the water response. Consequently, it is suggested that the depression of the water response caused by extracellular application of anions may result from hyperpolarization of the water receptor membrane generated by permeation of the anions in the stimulating solutions.

From the above inference all depressing anions can be considered to penetrate the receptor membrane. On the other hand, as shown in a previous paper (SHINGAI, 1977 a), all the depressing anions belong to the water structure-breaking anions. It is, therefore, implied that permeation of the depressing anions through the receptor membrane is associated with water structure-breaking actions of the anions. It is reported that anion permeability of the inhibitory post-synaptic membrane of crayfish depends on a combination of several factors, e.g., hydrated ion sizes and hydration energy (TAKEUCHI and TAKEUCHI, 1967, 1971). Thus, the difference in the magnitude of the depression of the water response among anions shown in the previous paper (SHINGAI, 1977 a) may be caused by a combination of several factors, including the water structure-breaking effect.

The water response can be observed with receptors in various kinds of animals, but there are great differences in the sensitivity of the receptors to various ions. Several hypotheses have been presented concerning the mechanisms of the water response as well as taste reception. BEIDLER (1967) has proposed that the binding of an anion to the cationic site of the receptor membrane produces an inhibitory effect. This hypothesis does not seem to be favorable to explain the findings on laryngeal water receptors in the rabbit, because anions added in the stimulating solutions showed three different effects, a facilitating effect (e.g., $\mathrm{F}^{-}$and $\left.\mathrm{SO}_{4}^{2-}\right)$, a depressing effect (e.g., $\mathrm{SCN}^{-}$and $\mathrm{Cl}^{-}$) and no effect (e.g., benzenesulfonate and trichloroacetate). Recently, MIYAKE et al. (1976) proposed that the water response was attributed to the diffusion potential at the membrane-solution interface. Although their hypothesis is attractive to explain the water response (not $\mathrm{Ca}^{2+}$ response) in the taste nerve of the frog, it is insufficient to interpret the facilitating effect of anions such as $\mathrm{F}^{-}$and $\mathrm{SO}_{4}^{2-}$ in the laryngeal water receptors used in the present experiment.

Laryngeal water receptors in the rabbit have not been identified yet histologically, but possible receptors to be considered are free nerve endings or taste buds. HARDING et al. (1978) have found that although laryngeal taste buds are rare or absent in newly-born kittens and monkeys, water units are numerous in the superior laryngeal nerve, and he suggested that taste buds were not associated with the water units. Since water units in kittens and monkeys resemble those in the rabbit in the response properties to various ions, it seems probable, therefore, that the water response dealt with in the present study is associated with free 
nerve endings.

\section{APPENDIX}

In general, the variation of the relative viscosity $\left(\eta_{\mathrm{r}}\right)$ with the molarity $C$ can be represented by the Jones and Dole equation

$$
\eta_{\mathrm{r}}=\eta / \eta_{0}=1+A C^{1 / 2}+B C
$$

where $\eta$ and $\eta_{0}$ are the viscosity of the solution and the solvent, respectively. $A$ is a constant depending on the long range coulombic forces and $B$ is a function of the size and hydration of the solute.

EINSTEIN $(1906,1911)$ has derived an expression for the hydrodynamic effect in the case of unsolvated spherical colloidal suspensions. He showed that

$$
\eta_{\mathrm{r}}=1+2.5 \phi
$$

where $\phi$ is the volume fraction of the solute. If this equation holds at the molecular level and if $\phi$ is expressed in terms of concentration in mols per liter, then Eq. (2) becomes

$$
\eta_{\mathrm{r}}=1+0.0025 V_{\mathrm{h}} C
$$

where $V_{\mathrm{h}}$ is the hydrodynamic volume in $\mathrm{cm}^{3} / \mathrm{mol}$. With an ideal solvent and with unsolvated solute particles, $V_{\mathrm{h}}$ should be given by the partial molal volume of the solute $\left(\bar{V}^{\circ}\right)$. Thus, in order to indicate the net water structural effect of a solute, the Einstein effect should be excluded. Consequently, the difference $B-0.0025 \bar{V}^{\circ}$ can be used as a criterion for determining the net structural effect of a solute.

$B$-values are given by the following equation derived from Eq. (1):

$$
\frac{\eta_{\mathrm{r}}-1}{\sqrt{\bar{C}}}=A+B \sqrt{C} \text {. }
$$

Figure 5 shows the relationship between $\left(\eta_{\mathrm{r}}-1\right) / \sqrt{C}$ and $\sqrt{C}$ for the results obtained in the present experiment. The data fitted the expected linear relationship quite satisfactorily. A $B$-value of an anion was given by the slope of the straight line for the anion.

On the other hand, a partial molal volume of a solute was obtained as follows. The molality $m$ was derived using the equation

$$
m=(1,000 C) /(1,000 d-C M)
$$

where $M$ is the molecular weight of the solute and $d$ is the density of the solution. Apparent molal volume $\phi_{\mathrm{v}}$ was calculated (in $\mathrm{cm}^{3} / \mathrm{mol}$ ) by the equation

$$
\phi_{\mathrm{v}}=\left[10^{3}\left(d-d_{0}\right) / m d d_{0}\right]+M / d_{0}
$$

where $d_{0}$ is the density of the solvent. For solutions of strong electrolytes, the variation of apparent molal volume with solute concentration may be represented by the equation 


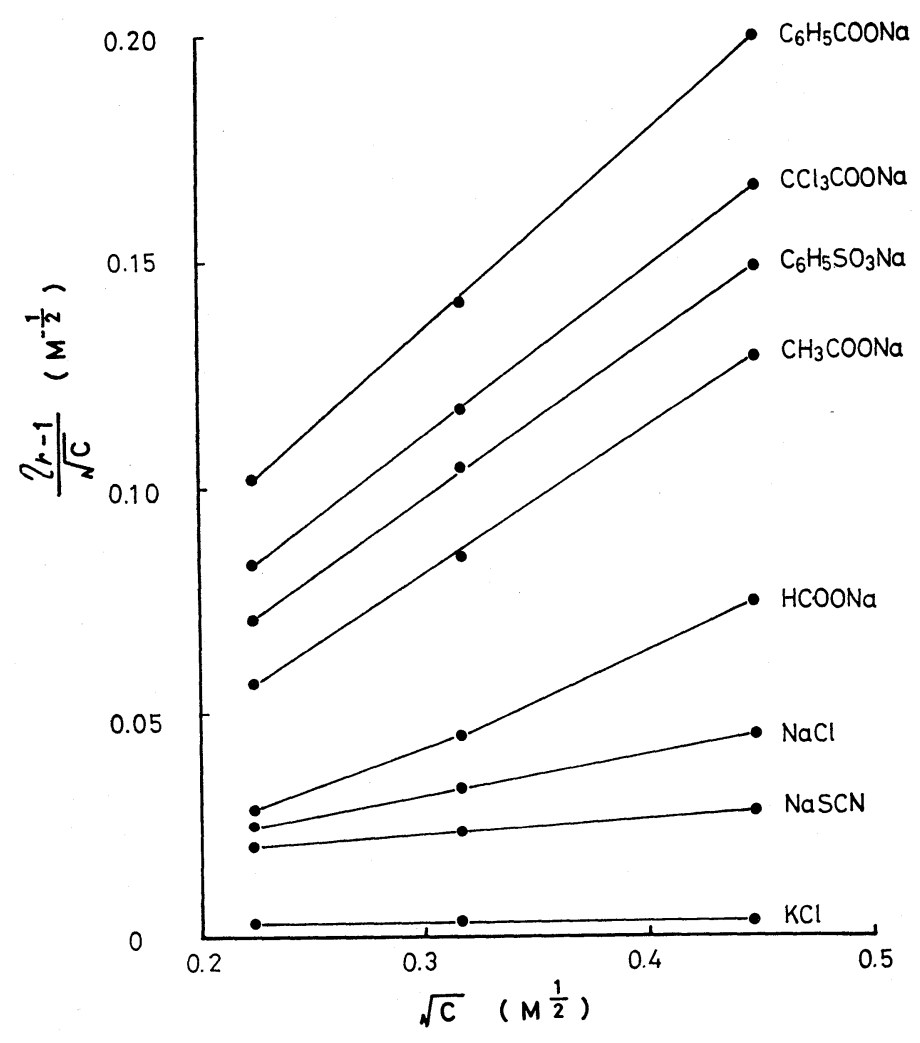

Fig. 5. Relations between $\left(\eta_{\mathrm{r}}-1\right) / \sqrt{C}$ and $\sqrt{C}$ for electrolyte solutions at $35.00^{\circ} \mathrm{C}$. $\eta_{\mathrm{r}}$ and $C$ denote the relative viscosity and the molarity, respectively.

$$
\phi_{\mathrm{v}}=\phi_{\mathrm{\vee}}{ }^{\circ}+A_{\mathrm{v}} C^{1 / 2}+j C
$$

in which $j$ is an empirical constant and $A_{\checkmark}$ is a theoretical constant which depends on the temperature and physical properties of the solvent; for water at $35^{\circ} \mathrm{C}$

$$
A_{\mathrm{v}}=2.046 \mathrm{~cm}^{3} \cdot l^{1 / 2} \cdot \mathrm{mol}^{-3 / 2} \quad \text { (MILLERO, 1971). }
$$

$\phi_{\vee}^{\circ}\left(=\bar{V}^{\circ}\right)$ was determined from plots of $\phi_{\mathrm{v}}-2.046 C^{1 / 2}$ against $C$ by extrapolation to infinite dilution.

The author wishes to express his thanks to Prof. H. Koyano and Dr. K. Yoshizaki for their valuable suggestions and discussions. He is also indebted to Mr. K. Ikeda for his technical assistance in this work.

\section{REFERENCES}

Araki, T., Ito, M., and Oscarsson, O. (1961) Anion permeability of the synaptic and nonsynaptic motoneurone membrane. J. Physiol. (Lond.), 159: 410-435.

Vol. 29, No. 4, 1979 
BeIDLER, L. M. (1967) Anion influences on taste receptor response. In: Olfaction and taste, II, ed. by HAYASHI, T., Pergamon Press, Oxford, pp. 509-534.

Boushey, H. A., Richardson, P. S., Widdicombe, J. G., and Wise, J. C. M. (1974) The response of laryngeal afferent fibres to mechanical and chemical stimuli. J. Physiol. (Lond.), 240: $153-175$.

Einstern, A. (1906) Eine neue Bestimmung der Moleküldimensionen. Ann. Phys., 19: 289-306.

EInSteIn, A. (1911) Berichtigung zu meiner Arbeit: "Eine neue Bestimmung der Moleküldimensionen." Ann. Phys., 34: 591-592.

FrANK, H. S. and WeN, W. Y. (1957) Structural aspect of ion-solvent interaction in aqueous solution: A suggested picture of water structure. Discuss. Faraday Soc., 24: 133-140.

HAGiwara, S. and TAKaHASHI, K. (1974) Mechanism of anion permeation through the muscle fibre membrane of an elasmobranch fish, taeniura lymma. J. Physiol. (Lond.), 238: 109-127.

HAMAGUCHI, K. and GeIDUSCHEK, E. P. (1962) The effect of electrolytes on the stability of the deoxyribonucleate helix. J. Am. Chem. Soc., 84: 1329-1338.

Harding, R., Johnson, P., and MCClelland, M. E. (1978) Liquid-sensitive laryngeal receptors in the developing sheep, cat and monkey. J. Physiol. (Lond.), 277: 409-422.

KAMINSKY, M. (1957) Ion-solvent interaction and the viscosity of strong electrolyte solution. Discuss. Faraday Soc., 24: 171-179.

LALIBERTÉ, L. H. and CONWAY, B. E. (1970) Solute and solvent structure effects in volumes and compressibilities of organic ions in solution. J. Phys. Chem., 74: 4116-4125.

Millero, F. J. (1971) The molal volumes of electrolytes. Chem. Rev., 71: 147-176.

Miyake, M., Kamo, N., Kurihara, K., and Kobatake, Y. (1976) Physicochemical studies of taste reception III. Interpretation of the water response in taste reception. Biochim. Biophys. Acta, 436: 843-855.

SHINGAI, T. (1977 a) Ionic mechanism of water receptors in the laryngeal mucosa of the rabbit. Jpn. J. Physiol., 27: 27-42.

SHINGAI, T. (1977 b) The responses to ionic solutions of laryngeal water receptors in the rat. J. Physiol. Soc. Jpn., 39: 377-378.

Storey, A. T. (1968) A functional analysis of sensory units innervating epiglottis and larynx. Exp. Neurol., 20: 366-383.

StoReY, A. T. and Johnson, P. (1975) Laryngeal water receptors initiating apnea in the lamb. Exp. Neurol., 47: 42-55.

TAKeUCHI, A. and TAKEUCHI, N. (1967) Anion permeability of the inhibitory post-synaptic membrane of the crayfish neuromuscular junction. J. Physiol. (Lond.), 191: 575-590.

TAKEUCHI, A. and TAKEUCHI, N. (1971) Anion interaction of the inhibitory post-synaptic membrane of the crayfish neuromuscular junction. J. Physiol. (Lond.), 212: 337-351.

Voet, A. (1937) Quantitative lyotropy. Chem. Rev., 20: 169-179.

Woodbury, J. W. and Mires, P. R. (1973) Anion conductance of frog muscle membrane: One channel, two kinds of pH dependence. J. Gen. Physiol., 62: 324-353. 